\section{Dynamics of inflammatory factors expression in ischemic brain tissue injury}

\author{
Tonko Marinović,1,2 Silvio Bašić,2,3 \\ Dominik Romić, ${ }^{1}$ Branimir Nevajda, ${ }^{4}$ \\ Lovorka Đerek,5 Jurica Maraković,1,6 \\ Marina Raguž 1
}

1Department of Neurosurgery, University Hospital Dubrava, Zagreb; 2Department of Neurology and Neurosurgery, Faculty of Dental Medicine and Health, University of J.J. Strossmayer Osijek, Osijek, Croatia; 3Department of Neurology, University Hospital Dubrava, Zagreb, Croatia; ${ }_{4}^{4}$ Basildon University Hospital, Basildon and Thurrock NHS Foundation Trust, Basildon, UK; 5Department of Chemistry, University Hospital Centre Sisters of Mercy, Zagreb, Croatia; 6Department of Surgery and Neurosurgery, School of Medicine, J.J. Strossmayer University of Osijek, Croatia

\begin{abstract}
Ischemic stroke is one of the most common cause of mortality and disability in the modern world. Still, therapeutic options remain modest. Aim of the study was to present dynamics of inflammatory factors expression ( $\mathrm{C}$ reactive protein, procalcitonin, interleukin 10) in patients after ischemic stroke. Our study included 101 patients divided in thrombolised and nonthrombolised groups. Inflammatory factors concentration in serum was determinate at admission, 24, 48 hours and seven days after the initial onset, while neurological assessment was measured at the admission, 24 hours, seven days and three months after the initial onset using National Institute of Health Stroke Scale and Rankin Scale. Certain pattern was observed in dynamics of inflammatory factors: intensive increase in first and second day after the stroke, followed by decrease till day seven in both groups. Additionally, thrombolised group showed significant neurological improvement. Although well investigated, the role of inflammatory factors in the ischemic stroke still stays controversial. High association of $\mathrm{C}$ reactive protein and interleukin 10 values suggest potential prognostic role in patient's follow-up, while the role of procalcitonin values still remains unclear.
\end{abstract}

\section{Introduction}

Ischemic stroke is the third leading cause of mortality and the most common cause of disability.1,2 Although numerous mechanisms are underlying the pathogenesis of the stroke, ischemic lesions and inflammations are responsible for its progression. ${ }^{1,2}$ Penumbra is the site of therapeutic action and its size plays great role in planning the treatment.3,4 After ischemic brain tissue injury reperfusion is necessary to stop the damage and establish normal brain function. ${ }^{4}$ Several inflammatory markers have been studied previously; $\mathrm{C}$ reactive protein (CRP) levels are significantly elevated in patients with cerebral ischemia for seven days, then subsequently decreases but remained elevated.5 Also, three to six months after injury, CRP levels remains higher than in the healthy population. 5 In addition, patients with elevated CRP values presented with increased mortality four years after stroke and increased incidence of recurrent stroke. 5,6 Number of studies consider the CRP values at the time of admission significant and independent of thrombolysis, while other studies deny prognostic value of CRP.2,7-9 The basal values of procalcitonin (PCT) in healthy people are low, therefore, elevated PCT values can be caused by infections, trauma or cardiogenic shock. ${ }^{10}$ Positive association between PCT value and outcome in patients with neurotrauma, subarachnoid hemorrhage or migraine was already presented.1113 Few studies tried to associate dynamics of PCT values with the size, development and prognosis of the ischemic stroke patients. ${ }^{14}$ On the other side, neuroprotective role of interleukin 10 (IL-10) in brain ischemia is largely accepted and confirmed in animal experiments, as well as in humans researches. ${ }^{15,16}$ The patients with decreased IL-10 concentration presented with a three times greater incidence of worsening neurological deficit within 48 hours after stroke. ${ }^{17}$ Previous studies revealed that post-ischemic IL-10 production can positively affect the regeneration of brain tissue by reducing inflammation and acting protective on surviving cells in the area of ischemia. ${ }^{18}$ Still, therapeutic options are modest. The only approved and effective drug is a recombinant tissue plasminogen activator (rt-PA), whose efficiency has been confirmed by numerous studies. 3,4,19,20 RtPA therapy, if performed three hours after the initial onset of symptoms, improves the outcome of patients with thromboembolic brain ischemia. ${ }^{20}$ So far, ideal brain ischemia therapy has not yet been found.

The aim of this study was to examine
Correspondence: Marina Raguž, Department of Neurosurgery, University Hospital Dubrava, Avenija Gojka Suska 6 Zagreb HR10000, Croatia.

Tel.: +38512902476 - Fax: +38512902934.

E-mail: marinaraguz@gmail.com

Key words: ischemic stroke, thrombolysis, C reactive protein, procalcitonin, interleukin 10 .

Contributions: TM designed the study and wrote the first draft of the manuscript. SB and BN obtained neurological assessment, patients follow up and the collection of clinical data presented. DR and LD preformed measuring the inflammatory factors for all measuring points. TM, SB and JM recruited the patients, interpreted the results and designed the figure and tables. MR contributed to the study concept and design and revised the manuscript. All authors read and approved the final version of the manuscript as submitted.

Conflict of interest: The authors declare no potential conflict of interest.

Funding: none.

Received for publication: 20 August 2019.

Accepted for publication: 9 September 2019

This work is licensed under a Creative Commons Attribution NonCommercial 4.0 License (CC BY-NC 4.0).

CC Copyright: the Author(s), 2019

Licensee PAGEPress, Italy

Neurology International 2019; 11:8282

doi:10.4081/ni.2019.8282

the possibility of monitoring and comparing the dynamics of inflammatory markers in order to predict the success of the therapy, primarily thrombolysis and possibly, find a pattern based on which the future therapeutic procedures can be estimated.

\section{Ethics approval and consent to participate}

This study was carried out in accordance with the recommendations of Ethical Board of the University Hospital Dubrava, Zagreb, Croatia with written informed consent from patients in accordance with the Declaration of Helsinki. The study was approved by the Institutional Review Board of the University Hospital Dubrava, Zagreb, Croatia.

\section{Materials and Methods}

The study included 101 patients, 41 females and 60 males. Average age of patients was $71.04 \pm 9.56$ years. Diagnosis 
of ischemic stroke was established both on the basis of clinical presentation and confirmed using multi slice computerized tomography (MSCT). All patients were given initial MSCT immediately upon arrival and control one within 24 hours after admission. Patients with transient ischemic attack, bleeding or other disease were excluded from the study. Using National Institutes of Health Stroke Scale (NIHSS) patients' clinical presentation and the success of the treatment were determined individually at the admission, 24 hours and seven days after initial onset. A clinical examination of each respondent was performed by an experienced neurologist. Further, based on applied therapy, patients were divided into two groups; thrombolised and non-thrombolised group. Out of total number of 101, 31 patient received thrombolytic therapy; alteplase was administered, dose $0.9 \mathrm{mg} / \mathrm{kg}$, up to a maximum of $90 \mathrm{mg}$. Inflammatory factors concentration (CRP, PCT, IL-10) in serum was also determinate at admission, 24 hours, 48 hours and seven days after the initial onset. The patients evaluation was done using the modified Rankin's Scale (mRS) three months after the initial onset of symptoms. Data analysis was performed using the Statistical Package for Social Sciences (SPSS), statistics software package (IBM Corporation, Armonk, New York, USA). Data were analyzed using Student's T-test. The association between individual parameters was assessed by Pearson's linear correlation coefficient. The level of statistical significance was set at $95 \%(\mathrm{P}<0.05)$.

\section{Results}

When comparing NIHSS score at the admission (day 0) and at day seven, statistically significant improvement in neurological presentation was observed in throm- bolised group $(\mathrm{P}<0,015)$, while in nonthrombolised group, no statistical significance was observed. Significant difference in CRP values in-between thrombolised and non-thrombolised group of patients was not observed (Figure 1A). Both PCT and IL-10 values presented with similar pattern (Figure 1B,C). In both groups of patients intensive increase of CRP values, as well as PCT and IL-10 values, was observed in first and second day, while at day seven, all measured values decreased, but remained slightly higher than at the admission (day $0)$.

PCT values measurements at day one, 24 hours after admission, revealed significant difference in-between males and females $(\mathrm{P}<0,046)$.

Positive association was observed in between NIHSS score at admission and day seven with the CRP values. Higher NIHSS score was accompanied with increased CRP values $(\mathrm{P}<0,001)$. Positive association of CRP values was observed initially, on first and second day, while at day seven, the correlation was weaker (Table 1). Additionally, positive association was observed in between NIHSS score at admission and at day seven with the levels of PCT and IL-10 values $(\mathrm{P}<0,01)$ (Table 2$)$. There was no significant association between NIHSS score at admission and IL-10 value at day seven, while positive association of IL-10 values and NIHSS score was observed at day seven (Table 3).

Associations of neurological outcome three months after stroke and inflammatory markers were performed in both thrombolised and non-thrombolised group of patients. In thrombolised group of patients, significant positive association for all inflammatory markers and neurological outcome was observed (Table 4). In nonthrombolised group of patients, similar results were observed (Table 4 ). In addition, initial NIHSS score at the admission and at day seven showed association with the patients outcome three months after the initial onset $(r=0.686, \mathrm{P}<0.01)$.

\section{Discussion}

The role of inflammatory markers in the pathophysiology of the ischemic stroke remains controversial. Initial CRP values in our patients were higher in non-thrombolised group and significantly increased than previously reported.21,22 As in literature, significant differences in the CRP values were observed between the first and second day.23,24 CRP dynamics showed increased values two to three days, while decreased values were described seven to about ten days after ischemic stroke. ${ }^{25,26}$ Audebert et al. confirms observed dynamics of CRP values. ${ }^{25}$ In addition, the authors showed lack of CRP elevation in case of successful thrombolysis. ${ }^{25}$ In our study, we showed a strong CRP values increase from initial values at patients admission to the second day in both groups, regardless of the performed thrombolysis.

Number of studies showed positive association between the increased initial CRP values with clinically worsen patients, as well as association with mortality within three months.5,18,21 The CRP values was showed to be independent prognostic factor for worsen or mortal outcome. In patients with thrombolysis performed, the results are ambiguous. Several authors showed association between initial values and mortality, while in other studies association has not been confirmed.9,27 We observed increased CRP values in a positive association with deteriorating neurological presentation among our patients. On contraire, no association between the CRP values and patients outcome was described in several studies. ${ }^{9}$ In thrombolised group of patients no association between initial NIHSS score and CRP
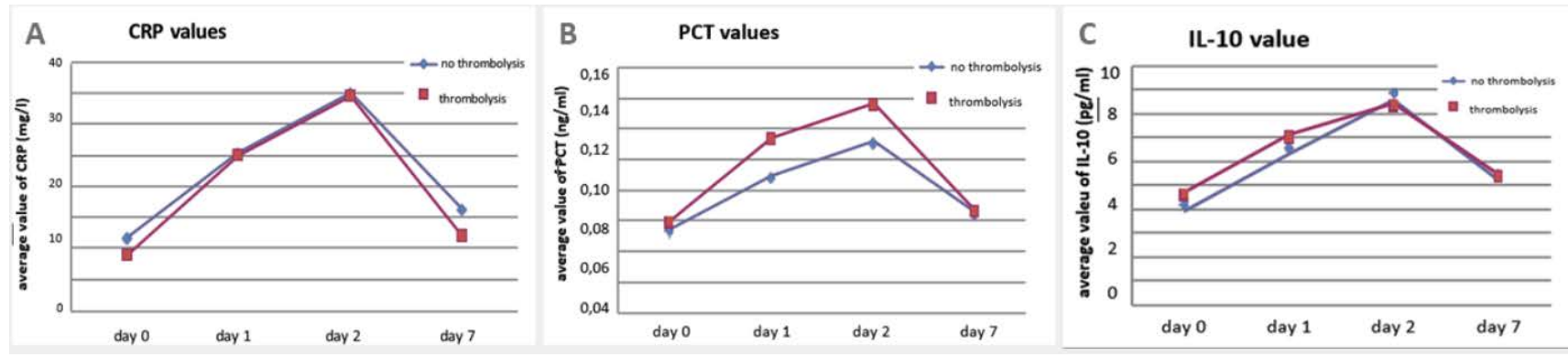

Figure 1. Dynamics of inflammatory factors expression in both groups measured at the admission, 24 hours, 48 hours and seven days after admission. All measured inflammatory markers, CRP (A), PCT (B) and IL-10 (C) showed similar pattern; intensive growth in first and second day, decreased values at day seven, but still slightly higher than at the admission. No statistically significant difference was observed in between groups. 
levels at day seven was observed.

The dynamics of PCT levels in serum of the patients with ischemic stroke have been poorly investigated. Association between increased PCT levels and poor neurological recovery in resuscitated patients after a heart attack was previously presented. ${ }^{14,15}$ In addition, no association of initial PCT values with neurological outcome or mortality was described. ${ }^{14}$ In our study, the initial PCT values in non-thrombolised group were decreased when comparing to throm- bolised group of patients. Miyakis et al. observed the highest PCT values in the second and third day after ischemic stroke. ${ }^{14}$ The PCT values dynamics follows the same pattern as the CRP values. The highest PCT values were observed on the second day,

Table 1. Associations of NIHSS score at admission and at day seven and CRP values at admission, 24 hours, 48 hours and seven days after admission in both groups of patients.

\begin{tabular}{|c|c|c|c|c|c|c|c|}
\hline & Thrombolysis & NIHSSO & NIHSS7 & CRPO & CRP1 & CRP2 & CRP7 \\
\hline NIHSSO & $\begin{array}{l}- \\
+\end{array}$ & $\begin{array}{l}1 \\
1\end{array}$ & $\begin{array}{c}0,86 \\
\mathrm{P}=0,000 \\
0,308 \\
\mathrm{P}=0,134\end{array}$ & $\begin{array}{c}0,704 \\
P=0,000 \\
0,788 \\
P=0,000\end{array}$ & $\begin{array}{c}0,66 \\
P=0,000 \\
0,554 \\
P=0,001\end{array}$ & $\begin{array}{c}0,668 \\
P=0,000 \\
0,496 \\
P=0,006\end{array}$ & $\begin{array}{c}0,528 \\
\mathrm{P}=0,000 \\
0,095 \\
\mathrm{P}=0,675\end{array}$ \\
\hline NIHSS7 & $\begin{array}{l}- \\
+\end{array}$ & $\begin{array}{c}0,86 \\
\mathrm{P}=0,000 \\
0,308 \\
\mathrm{P}=0,134\end{array}$ & 1 & $\begin{array}{c}0,657 \\
\mathrm{P}=0,000 \\
0,544 \\
\mathrm{P}=0,005\end{array}$ & $\begin{array}{c}0,71 \\
\mathrm{P}=0,000 \\
0,814 \\
\mathrm{P}=0,000\end{array}$ & $\begin{array}{c}0,702 \\
\mathrm{P}=0,000 \\
0,77 \\
\mathrm{P}=0,000\end{array}$ & $\begin{array}{c}0,531 \\
\mathrm{P}=0,000 \\
0,545 \\
\mathrm{P}=0,009\end{array}$ \\
\hline CRPO & + & $\begin{array}{c}0,704 \\
\mathrm{P}=0,000 \\
0,788 \\
\mathrm{P}=0,000\end{array}$ & $\begin{array}{c}0,657 \\
\mathrm{P}=0,000 \\
0,544 \\
\mathrm{P}=0,005\end{array}$ & 1 & $\begin{array}{c}0,925 \\
P=0,000 \\
0,767 \\
P=0,000\end{array}$ & $\begin{array}{c}0,909 \\
P=0,000 \\
0,749 \\
P=0,000\end{array}$ & $\begin{array}{c}0,779 \\
\mathrm{P}=0,000 \\
0,335 \\
\mathrm{P}=0,128\end{array}$ \\
\hline CRP1 & $\begin{array}{l}- \\
+\end{array}$ & $\begin{array}{c}0,66 \\
\mathrm{P}=0,000 \\
0,554 \\
\mathrm{P}=0,001\end{array}$ & $\begin{array}{c}0,71 \\
P=0,000 \\
0,814 \\
P=0,000\end{array}$ & $\begin{array}{c}0,925 \\
\mathrm{P}=0,000 \\
0,767 \\
\mathrm{P}=0,000\end{array}$ & 1 & $\begin{array}{c}0,989 \\
\mathrm{P}=0,000 \\
0,987 \\
\mathrm{P}=0,000\end{array}$ & $\begin{array}{c}0,895 \\
\mathrm{P}=0,000 \\
0,767 \\
\mathrm{P}=0,000\end{array}$ \\
\hline CRP2 & $\begin{array}{l}- \\
+\end{array}$ & $\begin{array}{c}0,668 \\
\mathrm{P}=0,000 \\
0,496 \\
\mathrm{P}=0,006\end{array}$ & $\begin{array}{c}0,702 \\
\mathrm{P}=0,000 \\
0,77 \\
\mathrm{P}=0,000\end{array}$ & $\begin{array}{c}0,909 \\
\mathrm{P}=0,000 \\
0,749 \\
\mathrm{P}=0,000\end{array}$ & $\begin{array}{c}0,989 \\
\mathrm{P}=0,000 \\
0,987 \\
\mathrm{P}=0,000\end{array}$ & $\begin{array}{l}1 \\
1\end{array}$ & $\begin{array}{c}0,907 \\
\mathrm{P}=0,000 \\
0,878 \\
\mathrm{P}=0,000\end{array}$ \\
\hline CRP7 & $\begin{array}{l}- \\
+\end{array}$ & $\begin{array}{c}0,528 \\
\mathrm{P}=0,000 \\
0,095 \\
\mathrm{P}=0,675\end{array}$ & $\begin{array}{c}0,531 \\
P=0,000 \\
0,545 \\
P=0,009\end{array}$ & $\begin{array}{c}0,779 \\
P=0,000 \\
0,335 \\
P=0,128\end{array}$ & $\begin{array}{c}0,895 \\
P=0,000 \\
0,767 \\
P=0,000\end{array}$ & $\begin{array}{c}0,907 \\
\mathrm{P}=0,000 \\
0,878 \\
\mathrm{P}=0,006\end{array}$ & 1 \\
\hline
\end{tabular}

Table 2. Associations of NIHSS score at admission and at day seven and PCT values at admission, 24 hours, 48 hours and seven days after admission in both groups of patients.

\begin{tabular}{|c|c|c|c|c|c|c|c|}
\hline & Thrombolysis & NIHSSO & NIHSS7 & PCTO & PCT1 & PCT2 & PCT7 \\
\hline NIHSSO & $\begin{array}{l}- \\
+\end{array}$ & $\begin{array}{l}1 \\
1\end{array}$ & $\begin{array}{c}0,86 \\
\mathrm{P}=0,000 \\
0,308 \\
\mathrm{P}=0,134\end{array}$ & $\begin{array}{c}0,779 \\
\mathrm{P}=0,000 \\
0,684 \\
\mathrm{P}=0,000\end{array}$ & $\begin{array}{c}0,517 \\
P=0,000 \\
0,015 \\
P=0,937\end{array}$ & $\begin{array}{c}0,178 \\
P=0,153 \\
0,006 \\
P=0,974\end{array}$ & $\begin{array}{c}0,602 \\
P=0,000 \\
0,268 \\
P=0,228\end{array}$ \\
\hline NIHSS7 & $\begin{array}{l}- \\
+\end{array}$ & $\begin{array}{c}0,86 \\
\mathrm{P}=0,000 \\
0,308 \\
\mathrm{P}=0,134\end{array}$ & $\begin{array}{l}1 \\
1\end{array}$ & $\begin{array}{c}0,767 \\
\mathrm{P}=0,000 \\
0,638 \\
\mathrm{P}=0,001\end{array}$ & $\begin{array}{c}0,525 \\
\mathrm{P}=0,000 \\
0,001 \\
\mathrm{P}=0,995\end{array}$ & $\begin{array}{c}0,156 \\
\mathrm{P}=0,231 \\
-0,002 \\
\mathrm{P}=0,994\end{array}$ & $\begin{array}{c}0,654 \\
\mathrm{P}=0,000 \\
0,653 \\
\mathrm{P}=0,001\end{array}$ \\
\hline PCT0 & $\begin{array}{l}- \\
+\end{array}$ & $\begin{array}{c}0,779 \\
\mathrm{P}=0,000 \\
0,684 \\
\mathrm{P}=0,000\end{array}$ & $\begin{array}{c}0,767 \\
\mathrm{P}=0,000 \\
0,638 \\
\mathrm{P}=0,001\end{array}$ & 1 & $\begin{array}{c}0,514 \\
\mathrm{P}=0,000 \\
0,08 \\
\mathrm{P}=0,674\end{array}$ & $\begin{array}{c}0,37 \\
\mathrm{P}=0,002 \\
0,082 \\
\mathrm{P}=0,672\end{array}$ & $\begin{array}{c}0,758 \\
\mathrm{P}=0,000 \\
0,581 \\
\mathrm{P}=0,005\end{array}$ \\
\hline PCT1 & $\begin{array}{l}- \\
+\end{array}$ & $\begin{array}{c}0,517 \\
\mathrm{P}=0,000 \\
0,015 \\
\mathrm{P}=0,937\end{array}$ & $\begin{array}{c}0,525 \\
\mathrm{P}=0,000 \\
0,001 \\
\mathrm{P}=0,995\end{array}$ & $\begin{array}{c}0,514 \\
P=0,000 \\
0,08 \\
P=0,674\end{array}$ & $\begin{array}{l}1 \\
1\end{array}$ & $\begin{array}{c}0,189 \\
\mathrm{P}=0,129 \\
0,999 \\
\mathrm{P}=0,000\end{array}$ & $\begin{array}{c}0,414 \\
\mathrm{P}=0,001 \\
0,094 \\
\mathrm{P}=0,676\end{array}$ \\
\hline PCT2 & $\begin{array}{l}- \\
+\end{array}$ & $\begin{array}{c}0,178 \\
\mathrm{P}=0,153 \\
0,006 \\
\mathrm{P}=0,974\end{array}$ & $\begin{array}{c}0,156 \\
\mathrm{P}=0,231 \\
-0,002 \\
\mathrm{P}=0,994\end{array}$ & $\begin{array}{c}0,37 \\
\mathrm{P}=0,002 \\
0,082 \\
\mathrm{P}=0,672\end{array}$ & $\begin{array}{c}0,189 \\
P=0,129 \\
0,999 \\
P=0,000\end{array}$ & 1 & $\begin{array}{c}0,342 \\
\mathrm{P}=0,006 \\
0,097 \\
\mathrm{P}=0,669\end{array}$ \\
\hline PCT7 & + & $\begin{array}{c}0,602 \\
\mathrm{P}=0,000 \\
0,268 \\
\mathrm{P}=0,228\end{array}$ & $\begin{array}{c}0,654 \\
P=0,000 \\
0,653 \\
P=0,001\end{array}$ & $\begin{array}{c}0,758 \\
P=0,000 \\
0,581 \\
P=0,005\end{array}$ & $\begin{array}{c}0,414 \\
\mathrm{P}=0,001 \\
0,094 \\
\mathrm{P}=0,676\end{array}$ & $\begin{array}{c}0,342 \\
\mathrm{P}=0,006 \\
0,097 \\
\mathrm{P}=0,002\end{array}$ & $\begin{array}{l}1 \\
1\end{array}$ \\
\hline
\end{tabular}


Table 3. Associations of NIHSS score at admission and at day seven and IL-10 values at admission, 24 hours, 48 hours and seven days after admission in both groups of patients.

\begin{tabular}{|c|c|c|c|c|c|c|c|}
\hline & Thrombolysis & NIHSSO & NIHSS7 & ILO & IL1 & IL2 & IL7 \\
\hline NIHSSO & $\begin{array}{l}- \\
+\end{array}$ & $\begin{array}{l}1 \\
1\end{array}$ & $\begin{array}{c}0,86 \\
\mathrm{P}=0,000 \\
0,308 \\
\mathrm{P}=0,134\end{array}$ & $\begin{array}{c}0,76 \\
\mathrm{P}=0,000 \\
0,546 \\
\mathrm{P}=0,002\end{array}$ & $\begin{array}{c}0,712 \\
P=0,000 \\
0,632 \\
P=0,000\end{array}$ & $\begin{array}{c}0,654 \\
\mathrm{P}=0,000 \\
0,49 \\
\mathrm{P}=0,007\end{array}$ & $\begin{array}{c}0,582 \\
\mathrm{P}=0,000 \\
0,186 \\
\mathrm{P}=0,408\end{array}$ \\
\hline NIHSS7 & $\begin{array}{l}- \\
+\end{array}$ & $\begin{array}{c}0,86 \\
P=0,000 \\
0,308 \\
P=0,134\end{array}$ & $\begin{array}{l}1 \\
1\end{array}$ & $\begin{array}{c}0,682 \\
P=0,000 \\
0,721 \\
P=0,000\end{array}$ & $\begin{array}{c}0,655 \\
P=0,000 \\
0,828 \\
P=0,000\end{array}$ & $\begin{array}{c}0,671 \\
\mathrm{P}=0,231 \\
0,71 \\
\mathrm{P}=0,000\end{array}$ & $\begin{array}{c}0,585 \\
\mathrm{P}=0,000 \\
0,717 \\
\mathrm{P}=0,000\end{array}$ \\
\hline ILO & $\begin{array}{l}- \\
+\end{array}$ & $\begin{array}{c}0,76 \\
\mathrm{P}=0,000 \\
0,546 \\
\mathrm{P}=0,002\end{array}$ & $\begin{array}{c}0,682 \\
\mathrm{P}=0,000 \\
0,721 \\
\mathrm{P}=0,000\end{array}$ & $\begin{array}{l}1 \\
1\end{array}$ & $\begin{array}{c}0,814 \\
\mathrm{P}=0,000 \\
0,829 \\
\mathrm{P}=0,000\end{array}$ & $\begin{array}{c}0,724 \\
\mathrm{P}=0,000 \\
0,682 \\
\mathrm{P}=0,000\end{array}$ & $\begin{array}{c}0,725 \\
\mathrm{P}=0,000 \\
0,651 \\
\mathrm{P}=0,001\end{array}$ \\
\hline IL1 & $\begin{array}{l}- \\
+\end{array}$ & $\begin{array}{c}0,712 \\
P=0,000 \\
0,632 \\
P=0,000\end{array}$ & $\begin{array}{c}0,665 \\
\mathrm{P}=0,000 \\
0,828 \\
\mathrm{P}=0,000\end{array}$ & $\begin{array}{c}0,814 \\
\mathrm{P}=0,000 \\
0,829 \\
\mathrm{P}=0,000\end{array}$ & $\begin{array}{l}1 \\
1\end{array}$ & $\begin{array}{c}0,915 \\
\mathrm{P}=0,000 \\
0,806 \\
\mathrm{P}=0,000\end{array}$ & $\begin{array}{c}0,76 \\
\mathrm{P}=0,000 \\
0,762 \\
\mathrm{P}=0,000\end{array}$ \\
\hline IL2 & $\begin{array}{l}- \\
+\end{array}$ & $\begin{array}{c}0,654 \\
\mathrm{P}=0,000 \\
0,49 \\
\mathrm{P}=0,007\end{array}$ & $\begin{array}{c}0,671 \\
\mathrm{P}=0,000 \\
0,71 \\
\mathrm{P}=0,000\end{array}$ & $\begin{array}{c}0,724 \\
\mathrm{P}=0,000 \\
0,682 \\
\mathrm{P}=0,000\end{array}$ & $\begin{array}{c}0,915 \\
P=0,000 \\
0,806 \\
P=0,000\end{array}$ & 1 & $\begin{array}{c}0,839 \\
\mathrm{P}=0,000 \\
0,675 \\
\mathrm{P}=0,001\end{array}$ \\
\hline IL7 & $\begin{array}{l}- \\
+\end{array}$ & $\begin{array}{c}0,582 \\
P=0,000 \\
0,186 \\
P=0,408\end{array}$ & $\begin{array}{c}0,585 \\
\mathrm{P}=0,000 \\
0,717 \\
\mathrm{P}=0,000\end{array}$ & $\begin{array}{c}0,725 \\
\mathrm{P}=0,000 \\
0,651 \\
\mathrm{P}=0,001\end{array}$ & $\begin{array}{c}0,76 \\
P=0,000 \\
0,762 \\
P=0,000\end{array}$ & $\begin{array}{c}0,839 \\
\mathrm{P}=0,000 \\
0,675 \\
\mathrm{P}=0,001\end{array}$ & 1 \\
\hline
\end{tabular}

with slightly higher PCT values in thrombolised group of patients. Gender-dependent PCT values dynamics showed higher values in female in all measured points. In non-thrombolised group of patients, a high positive association between the initial and day seven PCT values with NIHSS score at the same time point was observed. In thrombolised group of patients, a positive association between initial PCT values and initial and day seven NIHSS score were presented. These changes could be explained by a thrombolysis. Based on our results, it can be assumed that patients with increased initial PCT values, prognosis is worsening, regardless of the thrombolysis performed.

Initial IL-10 values, as well as dynamics of IL-10 values in ischemic stroke patients were well investigated. In our patients, the initial IL-10 value was increased in non-thrombolised group, as previously reported. 15 IL-10 values increase after brain ischemia in first 24 hours after thrombolysis, and present highest values between the second and seventh day. ${ }^{28,29} \mathrm{~A}$ negative association between IL-10 values in stroke patients and results of neurological presentation have been previously described in numerous studies, while several studies showed no association between IL-10 values and neurological outcome. ${ }^{28}$

Thrombolised group of patients present- ed with initially increased NIHSS score, as previously reported.21,27 Neurological outcome three months after ischemic stroke showed no statistically significant difference in between groups of patients. Therefore, the results imply efficiency of thrombolysis in patients with ischemic stroke. Positive association between initial and at day seven NIHSS score with mRS score three months after ischemic stroke was observed. Initial NIHSS and mRS score association decreased, positive association of NIHSS score at day seven increased, while association between initial and day seven NIHSS score disappears. Reducing the influence of initial neurological presentation on the outcome of treatment, and increasing the correlation with the neurological presentation on the seventh day after ischemic stroke could be considered as a contribution to the success of thrombolysis, as previously reported. ${ }^{30}$

\section{Conclusions}

Dynamics of inflammatory factors expression revealed similar pattern in both thrombolised and non-thrombolised groups of patients. We have showed that thrombolysis, as a therapeutic mode, doesn't affect dynamic of measured inflammatory markers. High correlation of the CRP and IL-10
Table 4. Associations of neurological outcome three months after ischemic stroke measured using mRS and inflammatory markers (CRP, PCT and IL-10) in both groups. In both groups of patients significant positive associations for all inflammatory markers and neurological outcome was observed.

\begin{tabular}{lcc} 
Thrombolysis & & \\
& & \\
CRP0 & 0,574 & 0,633 \\
& $\mathrm{P}=0,000$ & $\mathrm{P}=0,000$ \\
CRP1 & 0,652 & 0,777 \\
& $\mathrm{P}=0,000$ & $\mathrm{P}=0,000$ \\
\hline CRP2 & 0,683 & 0,76 \\
& $\mathrm{P}=0,000$ & $\mathrm{P}=0,000$ \\
CRP7 & 0,52 & 0,584 \\
& $\mathrm{P}=0,000$ & $\mathrm{P}=0,004$ \\
\hline PCT0 & 0,77 & 0,642 \\
& $\mathrm{P}=0,000$ & $\mathrm{P}=0,000$ \\
PCT1 & 0,566 & 0,124 \\
& $\mathrm{P}=0,000$ & $\mathrm{P}=0,515$ \\
\hline PCT2 & 0,312 & 0,13 \\
& $\mathrm{P}=0,011$ & $\mathrm{P}=0,501$ \\
PCT7 & 0,688 & 0,654 \\
& $\mathrm{P}=0,000$ & $\mathrm{P}=0,001$ \\
\hline IL0 & 0,666 & 0,803 \\
& $\mathrm{P}=0,000$ & $\mathrm{P}=0,000$ \\
IL1 & 0,699 & 0,902 \\
& $\mathrm{P}=0,000$ & $\mathrm{P}=0,000$ \\
\hline IL2 & 0,73 & 0,803 \\
& $\mathrm{P}=0,000$ & $\mathrm{P}=0,000$ \\
IL7 & 0,643 & 0,685 \\
& $\mathrm{P}=0,000$ & $\mathrm{P}=0,000$ \\
\hline & &
\end{tabular}


values suggest potential prognostic role in patients follow up, while role of PCT values yet remains unclear. Further investigation in this field are required, in order to find and develop the most effective treatment option.

\section{References}

1. Emsley HCA, Smith CJ, Tyrrell PJ et al. Inflammation in Acute Ischemic Stroke and its Relevance to Stroke Critical Care. Neurocrit Care 2007;9:125-38.

2. Ruiying Q, Yuan G, Dongzhe H, et al. Association between hs-CRP Levels and the Outcomes of Patients with Small-Artery Occlusion. Front Aging Neurosci 2016;8:191.

3. Bandera E, Botteri M, Minelli C, et al. Cerebral blood flow threshold of ischemic penumbra and infarct core in acute ischemic stroke: a systematic review. Stroke 2006;37:1334-9.

4. Markus HS. Cerebral perfusion and stroke. J Neurol Neurosurg Psychiatr 2004:75:353-61.

5. Eikelboom J, Hankey GJ, Baker RI, et al. C-reactive protein in ischemic stroke and its etiologic subtypes. J Stroke Cerebrovasc Dis 2003;12:74-81.

6. Youn CS, Choi SP, Kim SH, et al. Serum highly selective C-reactive protein concentration is associated with the volume of ischemic tissue in acute ischemic stroke. Am J Emerg Med 2012;30:124-8.

7. Matsuo R, Ago T, Hata J, et al. Plasma C-reactive protein and clinical outcomes after acute ischemic stroke: a prospective observational study. PLoS ONE 2016;11:e0156790.

8. Zhang YB, Yin $Z$, Han $X$, et al. Association of circulating high-sensitivity C-reactive protein with late recurrence after ischemic stroke. Neuroreport 2017;28:598-603.

9. Montaner J, Fernandez-Cadenas I, Molina C, et al. Poststroke C-reactive protein is a powerful prognostic tool among candidates for thrombolysis.
Stroke 2006;37:1205-10.

10. Meisner M, Adina H, Schmidt, J. Correlation of procalcitonin and C-reactive protein to inflammation, complications, and outcome during the intensive care unit course of multiple-trauma patients. Crit Care 2006;10:1-10.

11. Oconnor E, Venkatesh B, Mashongonyika $\mathrm{C}$, et al. Serum procalcitonin and C-reactive protein as markers of sepsis and outcome in patients with neurotrauma and subarachnoid haemorrhage. Anaesth Intensive Care 2004;32:465-70.

12. Li YM, Liu XY. Serum levels of procalcitonin and high sensitivity C-reactive protein are associated with long-term mortality in acute ischemic stroke. J Neurol Sci 2015;352:68-73.

13. Turan H, Horasanli B, Ugur M, et al. Procalcitonin levels in migraine patients. Canad J Neurol Sci 2011;38: 124-8.

14. Miyakis S, Georgakopoulos P, Kiagia $\mathrm{M}$, et al. Serial serum procalcitonin changes in the prognosis of acute stroke. Clin Chim Acta 2004;350:2379.

15. Christensen H, Boysen G, Christensen E, et al. Plasma cytokines in acute stroke. J Stroke Cerebrovasc Dis 2002; 11:72-9.

16. Jordán J, Segura T, Brea D, et al. Inflammation as therapeutic objective in stroke. Curr Pharm Des 2008; 14: 3549-64.

17. Vila N, Castillo J, Dávalos A, et al. Proinflammatory cytokines and early neurological worsening in ischemic stroke. Stroke 2000;31:2325-9.

18. Iadecola C, Anrather J. The immunology of stroke: from mechanisms to translation. Nat Med 2011;17:796-08.

19. Beridze M, Sanikidze T, Shakarishvili $\mathrm{R}$, et al. Selected acute phase CSF factors in ischemic stroke: findings and prognostic value. BMC Neurology 2011;11:41.

20. Hacke W, Kaste M, Bluhmki E, et al. Thrombolysis with alteplase 3 to 4.5 hours after acute ischemic stroke. New Engl J Med 2008;359:1317-29.
21. Den Hertog HM, van Rossum JA, van der Worp HB et al. C-reactive protein in the very early phase of acute ischemic stroke: association with poor outcome and death. J Neurol 2009;256:2003-8.

22. Wong AA, Read SJ. Early changes in physiological variables after stroke. Ann Indian Acad Neurol 2008;11:20720.

23. Tamam Y, Iltumur K, Apak I. Assessment of acute phase proteins in acute ischemic stroke. Tohoku J Exp Med 2005;206:91-8.

24. Muir KW, Tyrrell P, Sattar N, et al. Inflammation and ischemic stroke. Curr Opin Neurol 2007;20:334-42.

25. Audebert HJ, Rott MM, Eck T, et al. Systemic inflammatory response depends on initial stroke severity but is attenuated by successful thrombolysis. Stroke 2004;35:2128-33.

26. Idicula TT, Brogger J, Naess H, et al. Admission $\mathrm{C}$ - reactive protein after acute ischemic stroke is associated with stroke severity and mortality: The "Bergen stroke study." BMC Neurol 2009;9:18-27.

27. Topakian R, Strasak AM, Nussbaumer $\mathrm{K}$, et al. Prognostic value of admission C-reactive protein in stroke patients undergoing iv thrombolysis. J Neurol 2008;255:1190-6.

28. Mazzotta G, Sarchielli P, Caso V, et al. Different cytokine levels in thrombolysis patients as predictors for clinical outcome. Eur J Neurol 2004;11:377-81.

29. Tarkowski E, Rosengren L, Blomstrand $\mathrm{C}$, et al. Intrathecal release of pro- and anti-inflammatory cytokines during stroke. Clin Exp Immunol 1997;110: 492-9.

30. Sobolewski P, Sledzińska M, Szczuchniak W, et al. Intravenous thrombolysis patients with acute ischemic stroke: the analysis of the 100 cases. Part I. Characteristic of the patients and effectiveness of treatment. Prz Lek 2012;69:237-41. 